\title{
Residual Stress Condition of Tubular Laser Welds of an AZ31 Magnesium Alloy
}

\author{
Thomas Nitschke-Pagel ${ }^{1}$, Klaus Dilger ${ }^{2}$ \\ Institut für Füge- und Schweißtechnik, Technische Universität Braunschweig \\ Langer Kamp 8, D-38106 Braunschweig, Germany \\ 1t.pagel@tu-braunschweig.de, ${ }^{2}$ k.dilger@tu-braunschweig.de
}

\begin{abstract}
Keywords: Magnesium Alloy, Laser Welding, Welding Residual Stresses, Numerical Model
\end{abstract}

\begin{abstract}
Laser welded overlap tubular joints of an AZ31 magnesium alloy show an unexpected failure behaviour under axial and tensional cyclic loading. In the as-welded condition the fatigue cracks propagate not from the locations with the highest load stress concentration but from other sites. After a stress relief annealing at relatively low temperatures the crack initiation sites change to the expected locations This specific behaviour can be found on overlap connections of tubular joints as well as in aluminium as in magnesium alloy joints. Combined FE-calculations and residual stress measurements by means of XRD and neutron diffraction reveal that the particular constraint conditions of tubular joints lead to residual stress distributions which are distinguished remarkably from those of flat plates with linear welds due to the self-constraining geometry. The generation of a non-uniform circumferential residual stress condition with particular locations of high tensile and compressive residual stresses may explain the observed failure behaviour. After an annealing process with strong residual stress relaxation the fatigue cracks start at the expected locations. A shrinkage model for the description of the residual stress generation in tubular joints explains the local residual stresses over the entire thickness in the weld zones and in the adjacent material.
\end{abstract}

\section{Introduction}

Laser welding is a commonly used joining technique in the automotive industry and also in other technical fields especially for applications with materials which are difficult to weld with traditional techniques like spot welding or arc welding procedures [5]. Examples are heat treated or cold formed steels, precipitation hardened aluminium alloys and magnesium alloys, connections with plates of quite different thicknesses or mixed material connections. Here the strongly limited heat input and the small width of the laser welds enables to avoid greater loss of the material strength, the generation of smaller diffusion zones with detrimental intermetallic phases and finally the limitation of distortion problems. An important aspect is that due to the concentrated heat input high welding speed is possible which furthers also the productivity of the process but, however in combination with expected high tensile residual stresses.

A general problem of laser welding is that usually high quality requirements for the preparation of the edges of parts which shall be connected must be fullfilled because the process cannot compensate varying welding gaps. This is the reason, why laser welding for joining processes of thin walled structures is usually applied for overlap joints. Here the quality of the process can be guaranteed much easier without special preparation requests. The problem of such connections is that in overlap laser welded joints a sharp notch between the welded plates is necessarily created. Under cyclic load conditions this crack like notch is responsible for a very poor fatigue strength of these joints.

The load conditions in the surrounding of the gap can be described with local stress approaches which try to describe the local stress condition at the gap. This could be shown for steels and for aluminium alloys. A summary of local approaches which are based mainly on Neuber's rule can be 
used for the fatigue assessment is given in [1]. Two general problems must be taken into account. The notch radius is one of the most important parameters because it determines the amount of the effective stresses in the notch. Since neither the radius nor the local stresses can be exactly measured precisely the radius is set in practice conservative to zero which leads to a so called fictitious notch radius of $1 \mathrm{~mm}$. The second difficulty is that in the local approaches residual stresses due to welding are used like mean stresses. Since a RS measurement in the gap region is usually impossible the residual stresses used in these calculations are assumptive and usually set to the yield strength. Nevertheless recent investigations [2] on overlapping tubular joints of aluminium and magnesium alloys reveal that obviously residual stresses are of great importance for the failure behavior under cyclic loading. Fatigue test on tubular joints as shown in Fig.1 have shown that under axial loading the fatigue cracks start at the gap between the outer and the inner tube as expected. However in the as-welded state the failure occurs on the side of the outer tube, where the load stresses are necessarily lower due to the larger diameter. After a stress relief treatment the crack initiation site moves to the inner tube with the lower diameter. It is assumed that particular high tensile residual stresses at the gap on the outer tube side are responsible for this specific failure behavior [2].

\section{Investigations on laser welded tubular joints}

Overlapping tubular joints of a wrought AZ31 Magnesium-Aluminium-Zinc-alloy as shown in Fig. 1 were laser-welded using a $3 \mathrm{~kW} \mathrm{Nd:YAG-Laser.} \mathrm{The} \mathrm{welding} \mathrm{speed} \mathrm{was} 47 \mathrm{~mm} / \mathrm{sec}$, the heat input $23.2 \mathrm{~J} / \mathrm{mm}$. The shape of the weld seam is shown also in the micrograph Fig.1. The distribution of the microhardness (Martens hardness in $\mathrm{N} / \mathrm{mm}^{2}$ ) in the weld seam and in the adjacent zones show that obviously no significant changes of the mechanical properties are generated by the local heat input. The higher and lower hardness values in the center of the joint on both sides of the weld seam are related to measurement errors because the measurements were carried out by a surface scan where some points were too close to the gap.

The aim of the investigations was to determine the residual stresses in the zone of greatest interest, that is to say, at the gap between the welded tube shells. Therefore residual stress measurements at the Stress-Spec Instrument of the HeinzMeier-Leibnitz-Centre, Munich, were carried out by means of neutron diffraction. The setup of a measurement is presented in Fig.2. The residual stresses were measured in different layers in aswelded samples and after different static
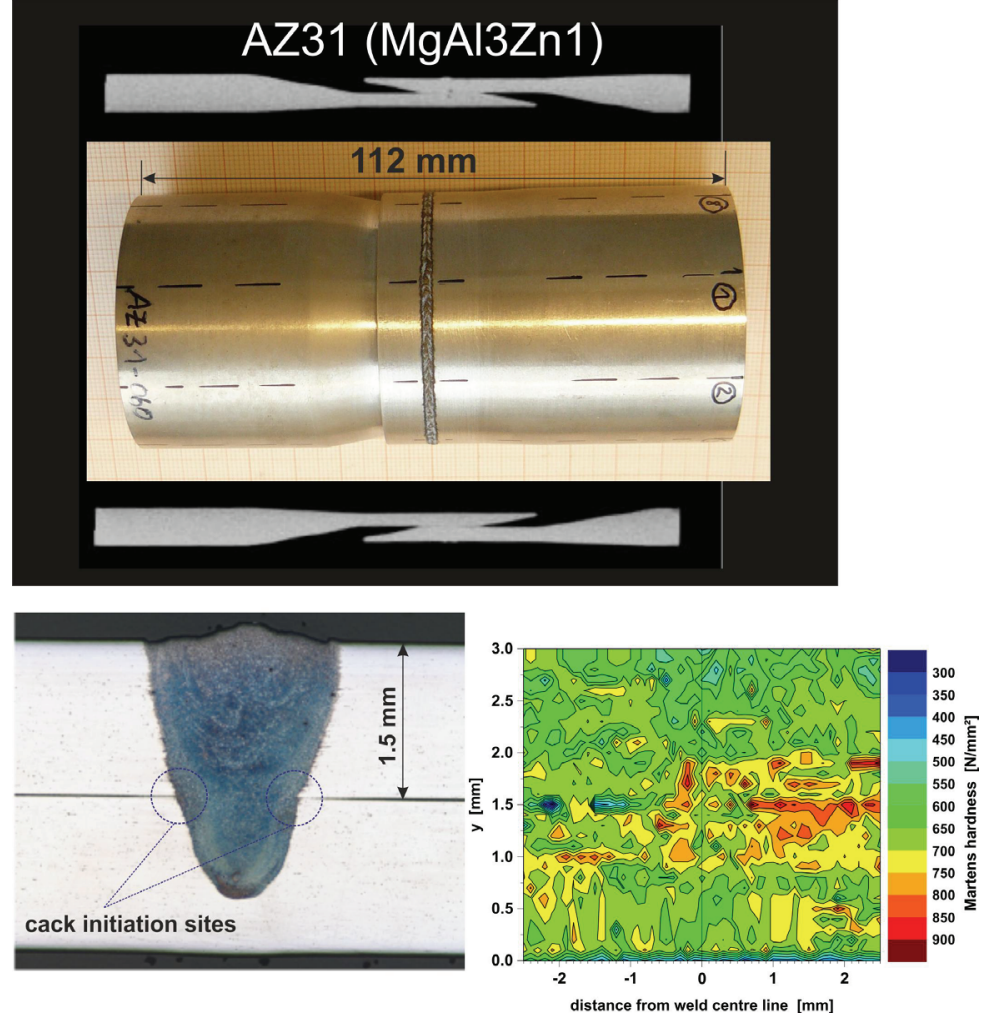

Fig. 1: Shape of the investigated tubular joints, micrograph with overview of the weld seam and throughthickness martens-hardness distribution. loads with regard to a load induced residual stress relaxation. The spatial resolution was $1 \times 5 \times 1 \mathrm{~mm}^{3}$. Additional surface measurements were carried out by means of X-ray diffraction in order to determine the near surface RS and texture pole figures. The measurements were performed with a standard $\psi$-diffractometer with an intersectioned Eulerian cradle using $\mathrm{CuK}_{\alpha}$-radiation. With regard 


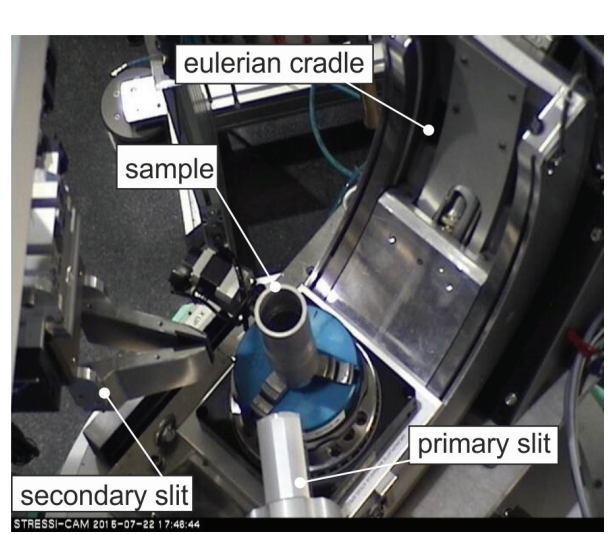

Fig.2: Experimental setup for the neutron measurements (StressSpec, MLZ). to the $\mathrm{RS}$ calculation the $\mathrm{X}$ ray elastic constant for the investigated material was experimentally determined to be $1 / 2 \mathrm{~s}_{2}=20.6510^{-6}$ $\mathrm{mm}^{2} / \mathrm{N}$.

Additionally the residual stresses in the tubular joints were calculated using a finite element model (Sysweld). The welding process was simulated with a gaussian heat source which was calibrated with measured temperature profiles. Finally the temperature profile was
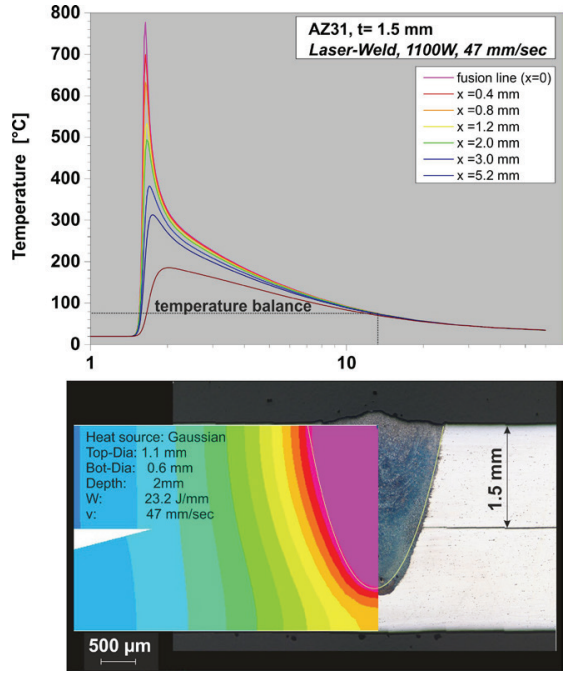

Fig.3: calculated cooling curves and temperature field with adjusted fusion line.

adjusted by fitting the fusion line to fusion line which can be identified in the micrograph (Fig.3). The required temperature dependent material properties were determined up to a temperature of $500^{\circ} \mathrm{C}$. The temperature dependency of the yield strength and the Emodulus is shown in Fig.4. Since the RS condition of an
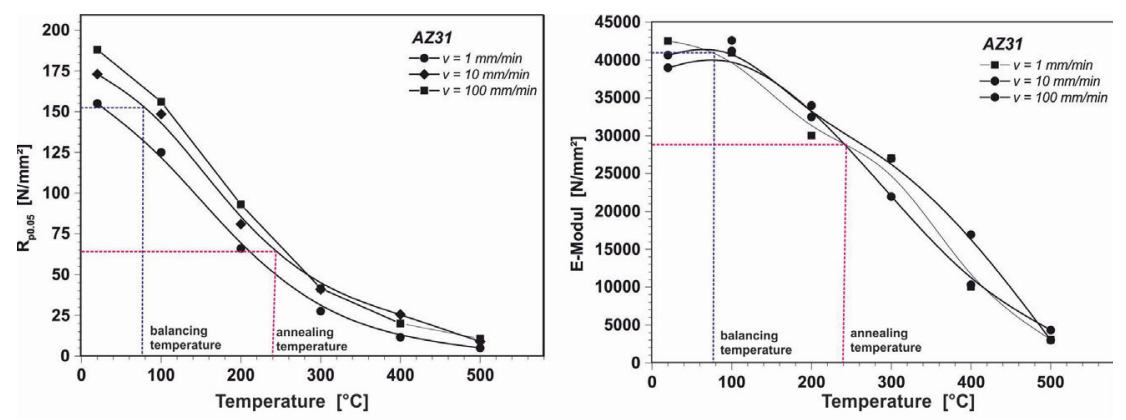

Fig. 4: Temperature depending mechanical properties of the magnesium alloy AZ31 AZ31 alloy is generated by a hindered shrinkage of the weld seam the yield strength at the balancing temperature limits the maximum size of the expected RS. Therefore the RS in the investigated samples should not exceed an amount of $160 \mathrm{MPa}\left(\mathrm{T}=80^{\circ} \mathrm{C}\right)$.

\section{Results of the investigation}

Fig.5 shows the results of residual stress calculations based upon the described FE-model. The distributions of the axial and hoop RS in the cross section reveal that the particular RS condition of the tubular joints shows a strong discrepancy to distributions which are expected in welded plates of similar thickness. Both RS components are not symmetrical in relation to the weld centre line and the highest tensile residual stresses in the hoop direction can be found on the root side and near the inner surface of the joints. Additionally a tensile RS peak is also present at the gap in the outer tube shell. In axial direction also nonsymmetrical RS can be found around the weld seam with a compressive peak at the outer surface and tensile RS peaks at the gap and at the inner surface. The high tensile peak of the axial component is located directly at the gap of the load-carrying part of the outer tube and this is an important sign which can be used to explain the unexpected failure behavior under axial loading in the as-welded condition. 
In Fig.6 the results of the neutron diffraction experiments are summarized. Here the axial direction (e.g. parallel to the axial load) RS in the described layers are presented in the as-welded state and after different loads. The load of $10 \mathrm{kN}$ correlates to a nominal shear stress of approximately 58 $\mathrm{N} / \mathrm{mm}^{2}$ while the fatigue limit at $10^{7}$ was found at 1.7 $\mathrm{kN} \quad\left(10 \mathrm{~N} / \mathrm{mm}^{2}\right)$. The measured RS distributions do not really match with the calculated ones. At certain locations (inner tube, inner layer) an agreement of the tendency of the residual stresses seems to be present
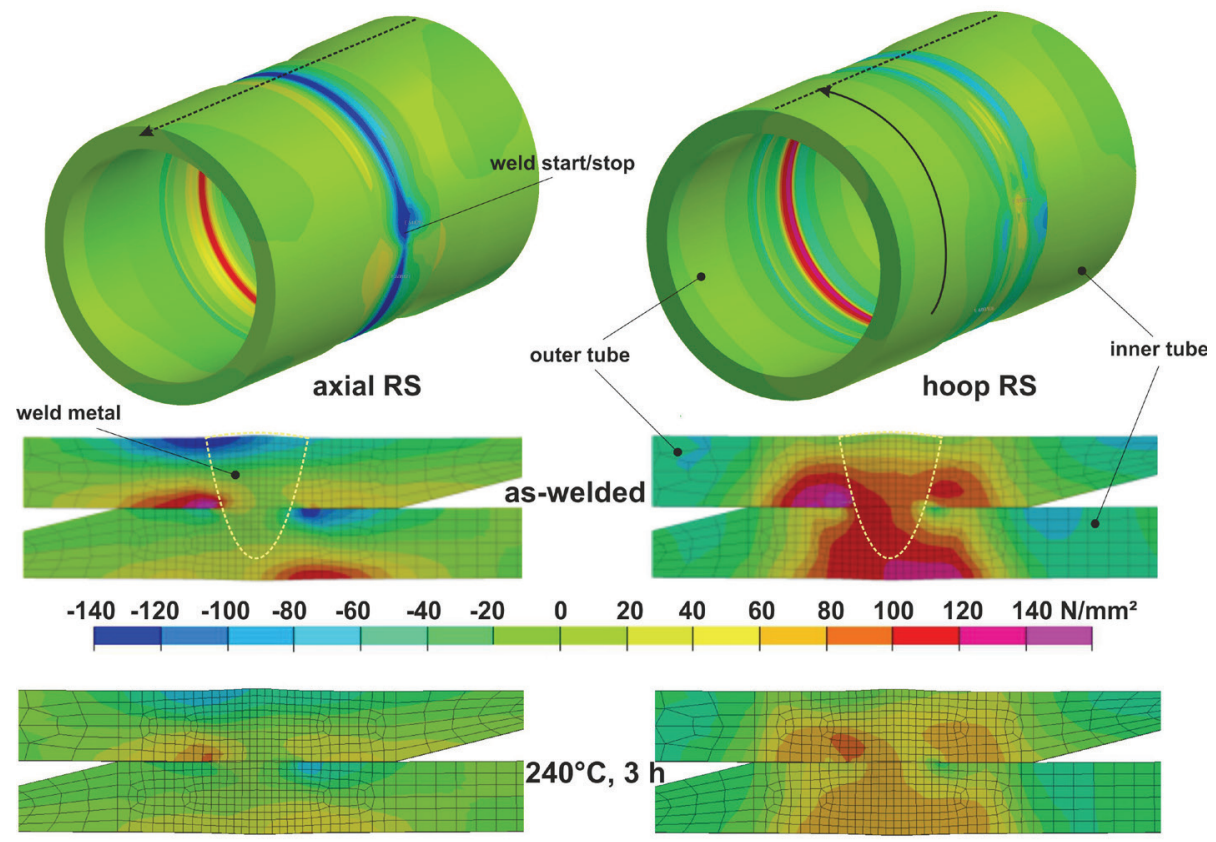

Fig.5: Calculated axial (left hand side) and hoop (right hand side) residual stresses in the as welded condition and after stress relief annealing at $240^{\circ} \mathrm{C}$. but the majority of the calculated characteristic RS peaks could not be found by the measurements.

Two aspects must be taken into account to explain the disagreement between the measured and the calculated RS. The average information depth of the neutron experiments covers a depth of $1 \mathrm{~mm}$ and that is to say that the residual stresses are representative for a distance of approximately $0.5 \ldots 0.6 \mathrm{~mm}$ from the related surface. With regard to a high local resolution in the weld gap region the FE-mesh size in the weld zone was chosen to 0.15 $\mathrm{mm}$ in depth. That means that the presented informations do not represent exactly the same layers. However it must be confessed that the neutron experiments are not really applicable to obtain the required local residual stresses with the required resolution. Higher local resolution was not applicable due to the poor diffraction conditions given by the material. Furthermore the experiments do not reveal a significant load induced relaxation of the residual
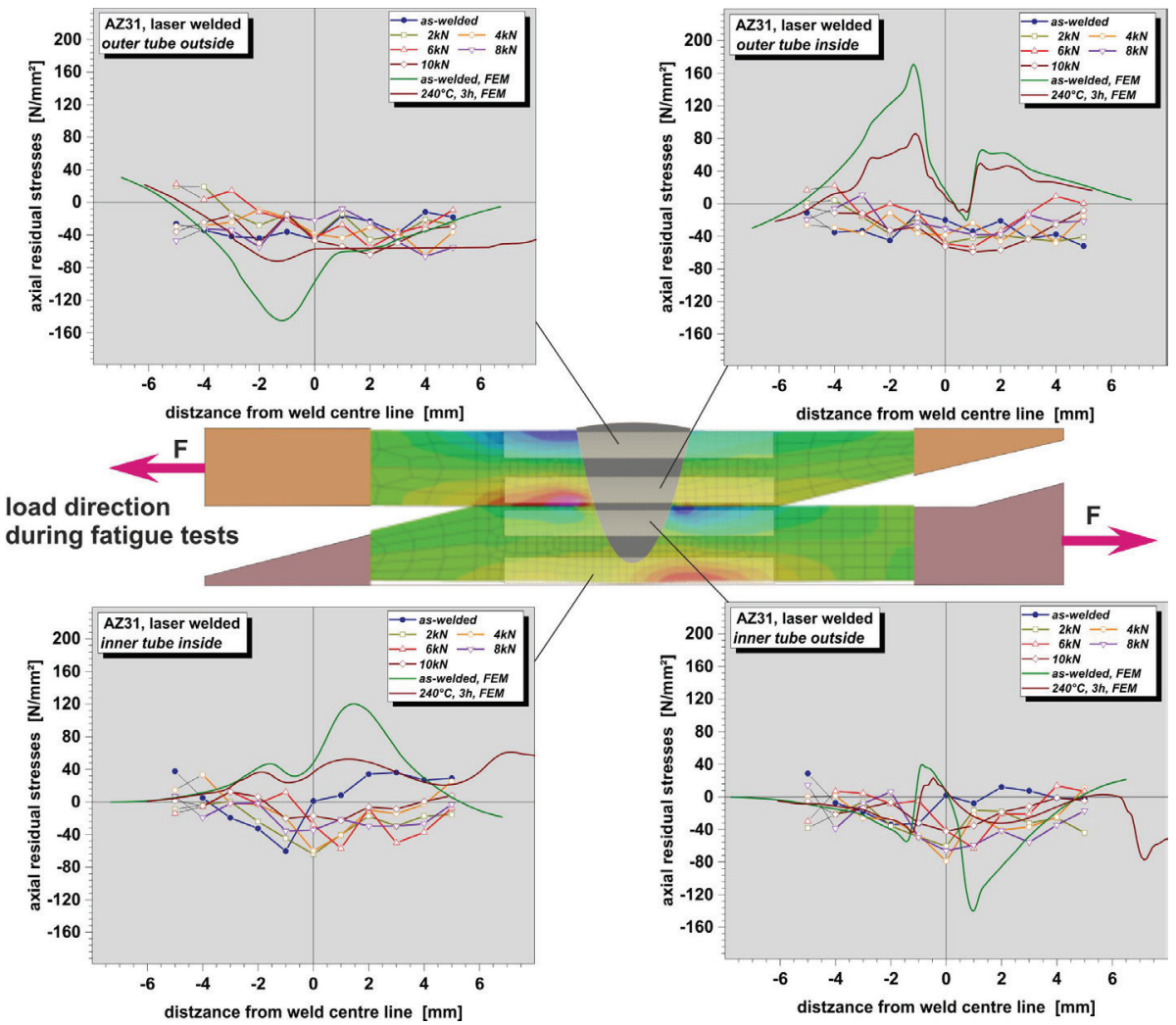

Fig. 6:Axial residual stresses in different depth layers measured with neutron diffraction after different axial loads. 

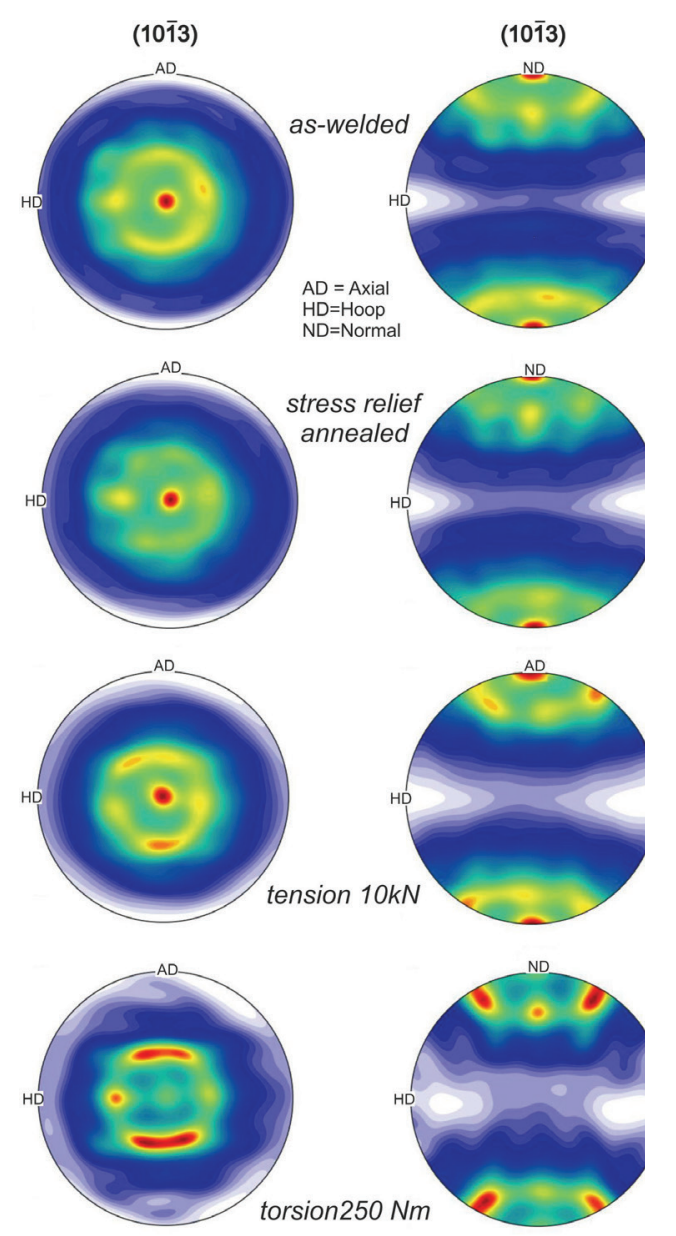

Fig.7: (1013)- pole figures

determined in the weld seam.

stresses which may also be caused by the low initial residual stresses in the investigated areas.

The quality of the measurement results are additionally strongly influenced by a distinctive texture which is present in the investigated material independent from the location in the weld zone or in the base material. Fig. 7 shows the pole figures measured in the weld seam with XRD using $\mathrm{CuK}_{\alpha}$-radiation at the (1013)-plane, which was used also for the residual stress measurements. The pole density distribution in the as-welded state and after stress relief annealing shows the fibre texture which is typical for the base material of cold rolled magnesium alloys $[3,4]$. It can be found in the weld material as well as in the base material. An annealing at $240 \% / 3 \mathrm{~h}$ does not change the observed structure. As the figures reveal after tensional and torsional loading the pole density distributions change due to the plastic deformations. Here the torsion leads to stronger changes in the crystal orientation. The consequence is that after different loads the quality of the results increases. In axial direction the measured residual stresses at the outer surface are more or less constant under tensional loading. This is not really surprising due to the initial compressive RS. However in the weld material the hoop RS decrease continuously with increasing shear stresses and that is an indicator of strong plastic deformations although the nominal load amount is relatively low in relation to the yield strength of the material (Fig.8). This behaviour is also represented by the width of the diffraction lines which increase after loading.

\section{Discussion and conclusions}

The results of the residual stress measurements have shown that in the investigated tubular samples the determination of residual stresses is rather difficult due to the influence of bad diffraction conditions. Comparing XRD-measurements which are published in literature the chosen (10 $\overline{1} 3$ )-lattice using $\mathrm{CuK}_{\alpha}$-radiation is not the recommended one [4] but in fact the experiments showed that other combinations did not allow measurements with higher reliability. Furthermore the measurements with $\mathrm{XRD}$ as well as with neutrons could performed at the same lattice plane. The most important problem was the influence of texture which complicated strongly the residual stress determination. Therefore a good agreement between the experimental results and the RS calculation could not be achieved. Nevertheless the calculated residual stress distributions are very feasible and can be used to evaluate the failure behavior of the fatigue loaded samples as described in the introduction. The particular residual stress distribution with

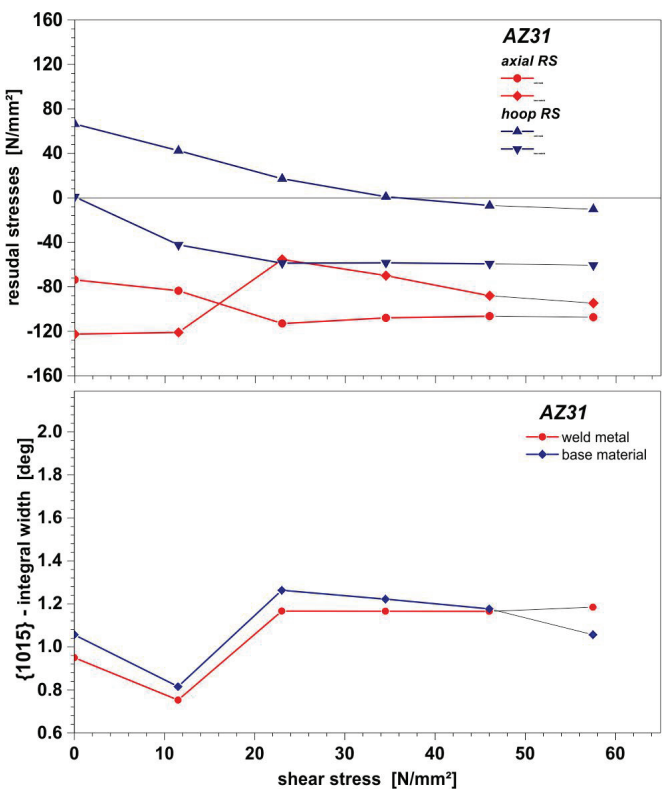

Fig.8: Relaxation of the axial residual stresses under axial loading. 
nonsymmetric tensile and compressive RS peaks as shown in Fig.5 can be explained by a shrinkage model as shown in Fig.7. The locally heated zone in the weld seam and its neighbourhood is acting like a "belt" in the cooling phase. This leads to an elastic reduction of the tube radius. The missing symmetry is due to the geometry of the overlapping tubes which furthers a heat accumulation at the free end of each tube shell. Therefore the free side of each tube is more or less RS free while the high RS peaks are concentrated on the opposite side with a higher constraint. The radius reduction generates a bending moment on the constraint side which generates a tensile stress peak in the outer tube and a tensile RS peak at the inner tube. Annealing at $240^{\circ}$ has shown a significant release of the RS peaks which makes the observed failure behaviour plausible. Therefore the calculated results can be evaluated as the more reliable ones than the measured ones. The change of the crack initiation sites due to the local amount of tensile residual stresses in the different stadiums is a definite indicator for the relevance of residual stresses for the fatigue behavior of the investigated joins.
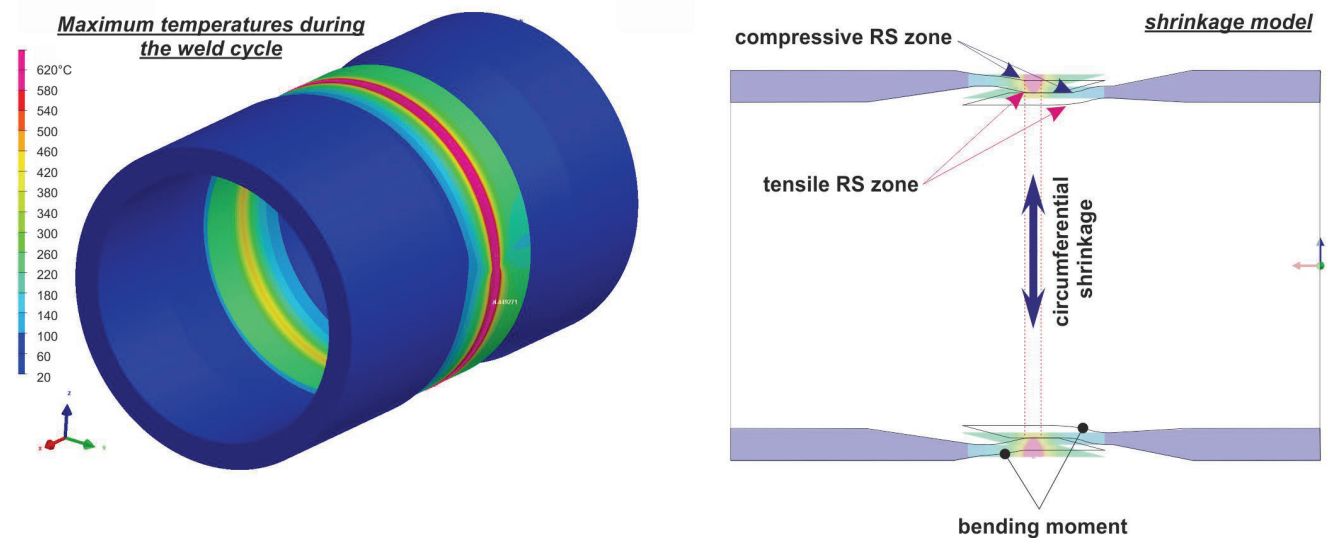

Fig.9: Shrinkage model of the residual stress generation in tubular joints.

\section{Acknowledgement}

The presented investigations were carried out in the research project Ni508/11-2 which was generously supported by the Deutsche Forschungsgemeinschaft (DFG). The authors would like to express their thanks for the support.

\section{References}

[1] Sonsino,C.M.; Fricke,W.; Radaj,D.: Fatigue assessment of welded joints by local approaches. $2^{\text {nd }}$ edition. Woodhead publishing Ltd., Cambridge (UK), 2006

[2] Exel,N.: PhD-Thesis, TH Darmstadt 2014, Shaker Verlag Aachen

[3] Noster,U.:PhD-Thesis, Universität Kassel 2003, Forschungsberichte aus dem Institut für Werkstofftechnik - Metallische Werkstoffe, Band 5.

[4] Krauß,M.: PhD-Thesis, Universität Kassel 2006, Forschungsberichte aus dem Institut für Werkstofftechnik - Metallische Werkstoffe, Band 8.

[5] Masny,H.; Ouaissa,B.: Bundesministerium für BMWi, Bonn * (2003) Seite 1-112 